\title{
Physical Endurance Capacity, Functional Status and Medical Complications in Spinal Cord Injured Subjects with Long-standing Lesions
}

\author{
N. Hjeltnes MD, T. Jansen MD, \\ Sunnaas Hospital, 1450 Nesodden, Norway
}

\section{Summary}

Seventy two spinal cord injured subjects (63 males and 9 females) with long-standing lesions ( $\bar{x} 110$ months, range 43-187) were admitted to the Sunnaas Hospital for routine examination (questionaire, neurological status, radiography, urodynamics, blood specimen, and physical endurance capacity during armergometry).

The subjects were divided into three groups with Low-(peak $\left.\mathrm{VO}_{2}<15 \mathrm{ml} / \mathrm{kg} / \mathrm{min}\right)$, Medium- $\left(15<\dot{\mathrm{V}} \mathrm{O}_{2}>25\right)$ and High- $\left(\dot{\mathrm{V}} \mathrm{O}_{2}>25\right)$ endurance capacity.

The rate of urinary tract infections (UTIs) and osteoporotic leg bones, was significantly reduced with increasing oxygen uptake $\left(p<0.05, X^{2}\right.$ test). Differences in scores for $A D L$-independency $(A D L=$ Activities of daily living) and ambulation on crutches with braces, were even more pronounced between the $L, M$ and $H$ groups $(p<0.001)$. The The same trends, although not always stastically significant, were also observed in a homogeneous group of paraplegic patients ( $n=43$, injury level below T6).

The results emphasise the importance of regular physical endurance activities to patient well-being, because relatively high endurance capacity was found to be related to less frequent medical complications, and to a higher degree of ADL self-independency.

Key words: Paraplegia; Tetraplegia; Physical endurance training; Oxygen uptake; Medical complications; Functional status.

In spite of the application of increasingly sophisticated technical aids, spinal cord injured subjects are still encouraged to become and to keep as physically fit as possible. Although earlier findings indicate that paraplegic athletes are more successful than non-athletes in avoiding the major medical complications to which they are at risk, nothing has been published to document the relationship between physical endurance capacity, functional status and the incidence of medical complications (Curtis and McClanahan, 1986; Stotts, 1985). The present investigation is a study to find if such a relationship existed in a group of non-selected subjects with spinal cord injuries admitted to our hospital for unrelated reasons. 


\section{Subjects}

Seventy two subjects (63 males and 9 females) with long-standing spinal cord injuries were admitted to the Sunnaas Hospital for follow-up examination (Table I). Most injury levels between C6 and the cauda equina were represented (Frankel A, B, C, D). However, the subjects had to be able to perform a maximal arm

Table I Groups of patients according to injury level

\begin{tabular}{|c|c|c|c|c|c|c|c|c|c|c|}
\hline \multirow{2}{*}{$\begin{array}{l}\text { Groups of } \\
\text { patients }\end{array}$} & \multirow[b]{2}{*}{ Injury level } & \multicolumn{2}{|c|}{ Patients in each } & \multirow{2}{*}{\multicolumn{2}{|c|}{$\begin{array}{l}\text { Mean } \\
\text { age } \\
\text { (years) }\end{array}$}} & \multirow{2}{*}{$\begin{array}{l}\text { Mean interval } \\
\text { between } \\
\text { injury and } \\
\text { investigation } \\
\text { (months) }\end{array}$} & \multicolumn{4}{|c|}{$\begin{array}{l}\text { peak } \dot{\mathrm{VO}_{2}}(\mathrm{ml} / \mathrm{kg} / \mathrm{min}) \\
\text { males females }\end{array}$} \\
\hline & & males & females & & & & $\overline{\mathbf{x}}$ & $\mathrm{SD}$ & $\overline{\mathbf{x}}$ & SD \\
\hline 1. TETRA & $\mathrm{C} 5-\mathrm{C} 8^{\star \star \star \star}$ & 10 & 0 & 36 & & 112 & 14 & $4 \cdot 6$ & & \\
\hline 2. HPARA ${ }^{\star}$ & T1-T6 & 6 & 0 & 33 & & 72 & 17 & $6 \cdot 5$ & & \\
\hline 3. MPARA ${ }^{\star}$ & $\mathrm{T} 7-\mathrm{T} 11$ & 14 & 2 & 38 & 26 & 118 & 26 & $8 \cdot 5$ & 23 & 1 \\
\hline 4. LPARA ${ }^{\star}$ & T12-L3 & 8 & 2 & 37 & 27 & 101 & 28 & $6 \cdot 8$ & 23 & $1 \cdot 5$ \\
\hline 5. CONUS $\star \star$ & L4-S2 & 11 & 1 & 53 & 35 & 109 & 24 & $7 \cdot 1$ & 40 & 0 \\
\hline 6. ICTETRA $A^{\star \star \star}$ & C5-C8 & 10 & 3 & 47 & 41 & 131 & 23 & $11 \cdot 0$ & 20 & $5 \cdot 3$ \\
\hline 7. ICPARA IC $^{\star \star \star}$ & T1-L3 & 4 & 1 & 47 & 29 & 93 & 23 & $6 \cdot 6$ & 12 & 0 \\
\hline
\end{tabular}

$\star \quad \mathrm{H}, \mathrm{M}, \mathrm{L}, \mathrm{=}$ High-, mid- and low-level injuries

$\star \star \quad$ Cauda equina injuries included

$\star \star \star \quad$ Incomplete injuries (Frankel C. D)

$\star \star \star \star$ The most caudally located unaffected medullary level

$\dot{\mathrm{V}}_{2}=$ oxygen uptake

ergometer test. Consequently the representation of tetraplegic patients was relatively low. The mean interval between injury and the date of the investigation of all subjects, was 110 months (range 43-187). The subjects were also divided into three groups with either high $(\mathrm{H})$, medium $(\mathrm{M})$ or low $(\mathrm{L})$ measured peak aerobic capacity (peak $\dot{\mathrm{VO}}_{2}$, Table II, Table III). The $\mathrm{X}^{2}$ test was used to find out whether the subjects within these groups also differentiated in functional status and in their

Table II The relation between physical endurance capacity (peak $\dot{\mathrm{VO}}_{2}$ ) and medical complications in spinal cord injured patients

\begin{tabular}{|c|c|c|c|c|c|c|c|c|c|c|}
\hline \multirow[t]{2}{*}{$\begin{array}{l}\text { Groups of } \\
\text { patients }\end{array}$} & \multirow[t]{2}{*}{$\begin{array}{l}\text { Peak } \dot{\mathrm{VO}}{ }_{2} \\
(\mathrm{ml} / \mathrm{kg} / \mathrm{min})\end{array}$} & \multicolumn{2}{|c|}{$\begin{array}{l}\text { Number } \\
\text { of patients }\end{array}$} & \multicolumn{2}{|c|}{ Pain \% } & \multicolumn{2}{|c|}{ Spasms \% } & $\begin{array}{l}\text { Chronic } \\
\text { (frequent) } \\
\text { UTI \% }\end{array}$ & \multicolumn{2}{|c|}{$\begin{array}{l}\text { Osteoporosi } \\
\text { (X-ray) \% }\end{array}$} \\
\hline & & & $\star$ & ns & ns & ns & ns & $\mathrm{s}$ & $\bar{s}$ & ns \\
\hline $\mathrm{L}(\mathrm{ow})$ & $<15$ & 14 & (3) & 72 & (67) & 86 & $(67)$ & $21 \quad(0)$ & 93 & $(100)$ \\
\hline $\mathbf{M}$ (edium) & $\geqslant 15 ; \leqslant 25$ & 34 & (22) & 62 & (63) & 65 & (63) & 12 (9) & 79 & $(82)$ \\
\hline H(igh) & $>25$ & 24 & (18) & 46 & (67) & 54 & (44) & 4 (6) & 50 & $(56)$ \\
\hline
\end{tabular}

\footnotetext{
$\star$ All numbers within the brackets concerns only paraplegic patients with injury level below T6 ns $=$ not statistically significant

$\mathrm{s}=\mathrm{p}<0.05$
}

history of medical complications. However, the groups have become relatively small so that statistical considerations have been reduced to a minimum. 
Table III The relation between physical endurance capacity (peak $\mathrm{VO}_{2}$ ) and functional status in spinal cord injured patients

\begin{tabular}{|c|c|c|c|c|c|c|c|c|c|}
\hline \multirow[t]{2}{*}{$\begin{array}{l}\text { Group of } \\
\text { patients }\end{array}$} & \multirow[t]{2}{*}{$\begin{array}{l}\text { Peak } \mathrm{VO}_{2} \\
(\mathrm{ml} / \mathrm{kg} / \mathrm{min})\end{array}$} & \multicolumn{2}{|c|}{$\begin{array}{l}\text { Number of } \\
\text { patients }\end{array}$} & \multicolumn{2}{|c|}{$\begin{array}{l}\text { Ambulates } \\
\text { with crutches } \\
\text { and braces }\end{array}$} & \multicolumn{2}{|c|}{$\begin{array}{l}\text { ADL } \\
\text { independent }\end{array}$} & \multicolumn{2}{|c|}{$\begin{array}{l}\text { Physical } \\
\text { endurance } \\
\text { training }\end{array}$} \\
\hline & & $\star$ & & ss & s & sss & ss & ns & \\
\hline $\mathrm{L}(\mathrm{ow})$ & $<15$ & 14 & ( 3 ) & 14 & (33) & 29 & ( 33$)$ & 21 & $(0)$ \\
\hline $\mathbf{M}$ (edium) & $\geqslant 15 ; \leqslant 25$ & 34 & (22) & 47 & (50) & 85 & ( 91$)$ & 27 & (32) \\
\hline H(igh) & $>25$ & 24 & (18) & 71 & (67) & 100 & (100) & 42 & (39) \\
\hline
\end{tabular}

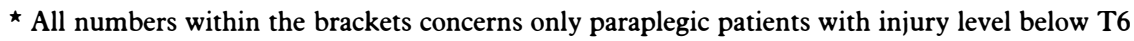

$\mathrm{s}=\mathrm{p}<0.05$, ss $\mathrm{p}<0.01$, sss $\mathrm{p}<0.001$

$\mathrm{ns}=$ not statistically significant

\section{Methods and procedure}

The subjects were interviewed with a questionnaire. As far as pain was concerned, they were categorised according to their answers into two groups: (1) having troublesome pain or (2) having no pain. Subjects suffering more than three urinary tract infections (UTIs) per year, that had been treated with antibiotics, were grouped in one group against the rest of the patients with fewer or without UTIs. All patients were examined neurologically; had radiographic examinations (bones, intravenous urography), and urodynamic investigations were performed (Dantec 2100 Uro-System). The radiograms of the femur and tibia were examined for osteoporosis in all our patients by an experienced radiologist, differentiating only between normal bone density and severely reduced density of the trabecular bone. To our knowledge no international standard is available for such classification. Blood specimens were taken to assess the $\mathrm{Hb}, \mathrm{SR}$, Creatinin, Albumin, and ALP (alcaline phosphatases). The maximal arm exercise was performed on an electrically braked and load stabilised ergometer (Jaeger, Germany). The fraction of $\mathrm{O}_{2}$ and $\mathrm{CO}_{2}$ in expiratory air as well as the expiratory volume $\left(\mathrm{V}_{\mathrm{E}} \mathrm{l} / \mathrm{min}\right)$ were continuously recorded by means of the Gould system $9000 \mathrm{IV}$, which also automatically calculated the oxygen uptake every 20 seconds during the maximal exercise bouts (Hjeltnes 1986).

\section{Results}

The mean peak $\dot{\mathrm{VO}}_{2}$ of our subjects (Table I) was much lower than the corresponding values for wheelchair athletes (Wicks et al., 1983). The individual values were more scattered than during primary rehabilitation (Hjeltnes, 1984).

The number of patients in the $\mathrm{L}$ group, however, reflects the relatively low number of tetraplegic patients.

Chronic urinary tract infections (UTI) and osteoporotic leg bones were reported less frequently with increasing oxygen uptake (Table II). A corresponding trend (not statistically significant), was noted for pain and muscle spasms (Table II). When only paraplegic patients with injury levels below T6 were included (Table II, numbers within brackets), there was no longer any difference in pain reports and UTIs, a small difference in muscle spasms, but still an obvious trend, although 
not statistically significant, in reported numbers of osteoporotic legs. At least one pressure sore was reported per patient since being discharged from primary rehabilitation in approximately $50 \%$ of the subjects without any statistically significant difference being found between the $\mathrm{L}, \mathrm{M}$ and $\mathrm{H}$ groups. While less than $1 / 3$ of the subjects with low endurance capacity were independent during daily life activities (ADL), $100 \%$ of the subjects of the $\mathrm{H}$ group reported ADL independency $(p<0.01)$. Ambulation with crutches and braces were reported 5 times more frequently in the $\mathrm{H}$ group than in the $\mathrm{L}$ group $(\mathrm{p}<0 \cdot 1$, Table III). Participation in endurance training was also reported most frequently in the $\mathbf{H}$ group. When only paraplegic subjects with injury levels below T6 were included (Table III, numbers within brackets), there were still significant differences between the groups $(\mathrm{L}, \mathrm{M}, \mathrm{H})$ concerning ADL independancy $(\mathrm{p}<0.01)$ and ambulation with crutches and braces $(\mathrm{p}<0.05)$. Low level paraplegic subjects with low endurance capacity did not participate in endurance training at all (Table III).

\section{Discussion}

In this study low physical endurance capacity was found to coexist with an increased number of medical complications and more dependency during daily life activities. These complications were usually not so serious that the patients were forbidden to train physically. Since systematic physical endurance training in such patients relatively easily increases their endurance capacity by more than $30 \%$ (Hjeltnes 1984), they can be moved from group L to group $\mathrm{H}$, which was found to co-exist with less medical complications, and more independancy in daily living. Therefore, although no causal relationship has been proven, physical endurance training is recommended as a prophylactic measure against medical complications. Physical fitness measured as peak $\mathrm{VO}_{2}$ will favour the subjects with anatomically low injury levels (Hjeltnes 1984, Hjeltnes 1986). Such subjects have fewer chronic UTI and are less likely to have osteoporetic leg bones, for unrelated reasons. However, statistically significant differences were found between the $\mathrm{L}, \mathrm{M}$ and $\mathrm{H}$ groups when only paraplegic patients (injury levels below T6) were included, showing also the same trends in a homogenous group of paraplegic patients (Table II, Table III).

\section{References}

Curtis KA, MCClanahan 1986 Health, vocational, and functional status in spinal cord injured athletes and nonathletes. Archives of Physical Medicine and Rehabilitation 67:862-865.

HJELTNES N 1984 Control of medical rehabilitation of para- and tetraplegics by repeated evaluation of endurance capacity. International Fournal of Sports Medicine 5:171-174.

HJELTNES N 1986 Cardiorespiratory capacity in tetra- and paraplegia shortly after injury. Scandinavian fournal of Rehabilitation Medicine 18:65-70. 
Stotrs KM 1985 Health maintenance: Paraplegic athletes and nonathletes. Archives of Physical Medicine and Rehabilitation 67:109-114.

Wicks JR, OldRIDGe NB, CAMERON JB, JoNes N̈L 1983 Arm cranking and wheelchair ergometry in elite spinal cord injured athletes. Medicine and Science in Sports and Exercise 15:224-230. 